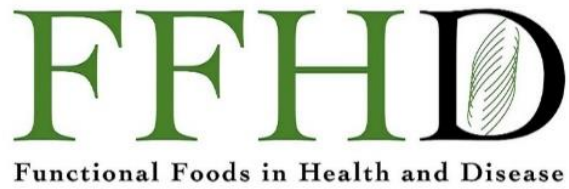

\title{
A review of Kurozu, amber rice vinegar made in pottery jars
}

\author{
Yoshihiko Shibayama', Hiroaki Kanouchi ${ }^{2}$, Akira Fujii $^{3}$, and Masanobu Nagano ${ }^{3}$
}

\begin{abstract}
${ }^{1}$ Department of Drug Formulation, Faculty of Pharmaceutical Sciences, Health Sciences University of Hokkaido, 1757 Kanazawa, Tobetsu-cho, Ishikari-gun, Hokkaido 061-0293, Japan, ${ }^{2}$ Department of Clinical Nutrition, School of Comprehensive Rehabilitation, Osaka Prefecture University, 3-7-30 Habikino-shi, Osaka 583-8555, Japan, ${ }^{3}$ Sakamoto Kurozu, Inc., 21-15, Uenosono-cho, Kagoshima 890-0052, Japan
\end{abstract}

Corresponding author: Yoshihiko Shibayama, Ph.D., Department of Drug Formulation, Faculty of Pharmaceutical Sciences, Health Sciences University of Hokkaido, 1757 Kanazawa, Tobetsu-cho, Ishikari-gun, Hokkaido 061-0293, Japan

Submission Date: April 17 7 th 2020; Acceptance Date: June 15 1 th 2020 ; Publication Date: June $22^{\text {nd }}, 2020$

Please cite this article as: Shibayama Y., Kanouchi H., Fujii A., and Nagano M. A review of Kurozu, amber rice vinegar made in pottery jars. Functional Foods in Health and Disease. 2020; 10(6): 254-264. DOI: https://doi.org/10.31989/ffhd.v10i6.713

\begin{abstract}
:
Brewed rice vinegar, Kurozu, is a traditional Japanese vinegar with a dark amber color. Kurozu is produced in a regional area of Japan using traditional techniques and made inside handcrafted pottery jars. Kurozu is used as both a seasoning and a healthcare supplement. In vitro and in vivo investigations of ingredients in Kurozu have been carried out. Studies of the functional aspects of Kurozu began in the 1980s, and the health promoting and disease preventing effects of Kurozu have since been elucidated. It was reported that Kurozu improved the symptoms of hypertension, allergies, hypercholesterolemia, enhanced carbohydrate metabolism, and inhibited tumor growth. Kurozu-Moromi is an insoluble product created from the fermentation of Kurozu. Kurozu-Moromi also shows valuable properties, including improvement in dyslipidemia, prevention of hyperglycemia, antitumor effect, and antiallergic activity.
\end{abstract}

Keywords: Amber color, Brewed vinegar, Functionality, Moromi, Pottery jars

CFFC 2020. This is an Open Access article distributed under the terms of the Creative Commons Attribution 4.0 License (http://creativecommons.org/licenses/by/4.0). 
INTRODUCTION: Vinegar has been used as a seasoning for several thousand years. In ancient times, there was a record of Hippocrates using vinegar as medication. Traditional vinegar is produced from raw materials containing sugars or starches, such as grape, apple, malt, and rice. The production of vinegar typically involves a first fermentation where simple sugars in the raw material are converted to alcohol by yeasts. The resultant alcohol is further oxidized into acetic acid by acetic acid bacteria ( $A A B)$, which are present everywhere in the environment [1].

Kurozu, which contains rice, spring water, and koji, is made using pottery jars. Koji is a culture of a certain mold that grows on rice and is used when it produces fermentation products, such as rice wine. Kurozu changes to an amber color with aging (Figure 1). The change in color was the origin of black vinegar, and it was named "Kurozu" in 1975 by Sakamoto Kurozu, Inc. "Kuro" indicates black color, while "zu" indicates vinegar in Japanese. It is believed that sugars react with amino acids by aminocarbonylation, resulting in the product's amber color.

Kurozu has been produced in the Fukuyama region of Kagoshima prefecture for about 200 years. The Fukuyama region is suitable for brewing vinegar because of its warm climate and ready supply of spring water [2, 3]. Kurozu is handcrafted using traditional techniques and craftsmanship.

In Japan, there are many regional brand products that have obtained strong reputations because of their unique production methods and natural characteristics. The Ministry of Agriculture, Forestry and Fisheries (MAFF) of Japan certifies Kurozu as a specific agricultural product.

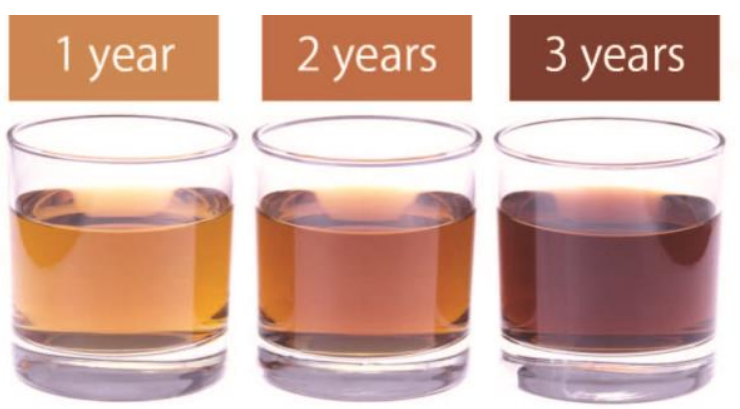

Figure 1. Color change of Kurozu with aging. Left, 1 year old; Middle, 2 years old; Right, over 3 years old.

The Geographical Indication (GI) Act protects the names of specific agricultural, forestry, and fishery products and foodstuffs and was implemented by MAFF in accordance with a treaty with the World Trade Organization, which defines intellectual property rights of specific agricultural products.

BREWING: Kurozu is produced in outdoor environments using Japanese pottery jars (typical size: trunk diameter $40 \mathrm{~cm}$, caliber $14 \mathrm{~cm}$, height $62 \mathrm{~cm}$, volume 54 L; Figure 2, 3). Koji-containing steamed rice, steamed rice, spring water, and Koji are layered in the jar. Koji is sprinkled on the surface of the water at a constant thickness (Figure 3). Kurozu is brewed twice a year during spring and autumn. Koji is widely used in Japanese fermented foods, including sake (alcoholic beverage), soy sauce, and rice vinegar. Most Japanese fermented foods contain koji (rice fermented with the non-pathogenic fungus Aspergillus oryzae or $A$. luchuensis) as the saccharifying agent of the starch contained in crops. Koji initiates a dynamic microbial succession, resulting in the saccharification of starch and subsequent alcoholic fermentation [4-7]. Kurozu does not require the addition of yeast or acetobacter to the pottery jars or thermoregulation of the brewing process (Figure 4). 


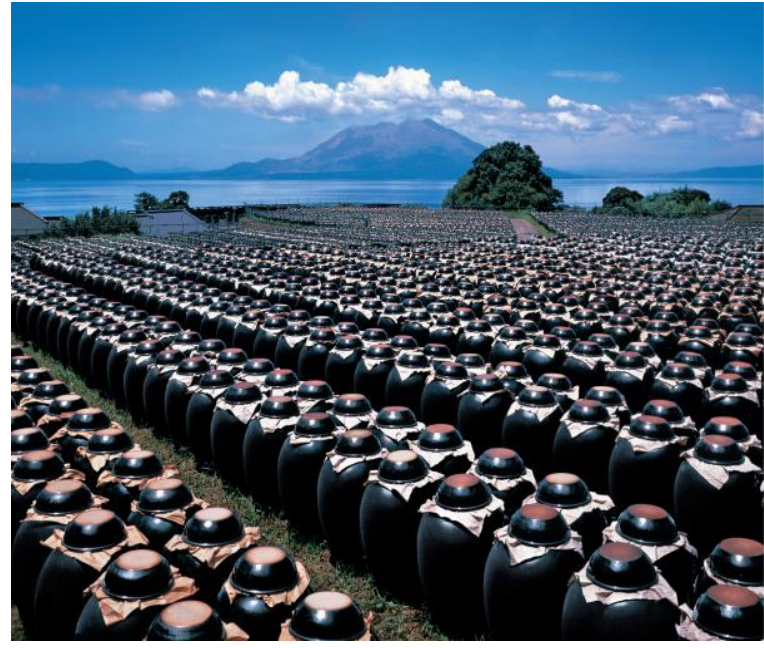

Figure 2. Pottery jars are placed outdoors for the brewing process

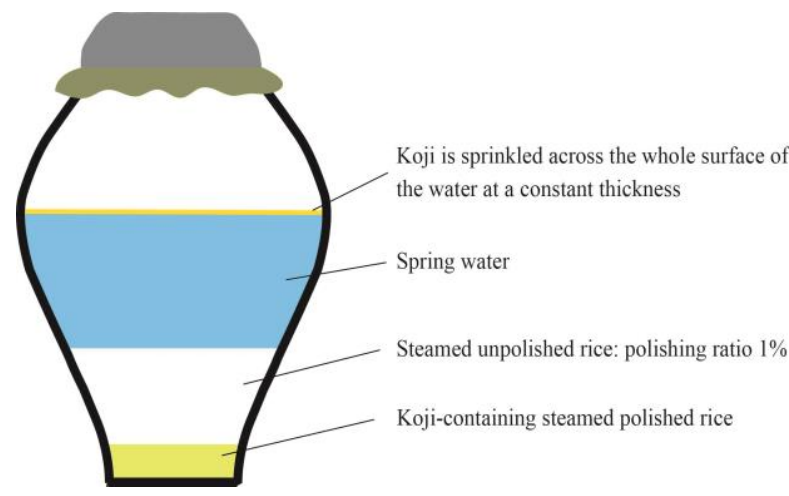

Figure 3. Cross-section of the layered materials in a pottery jar

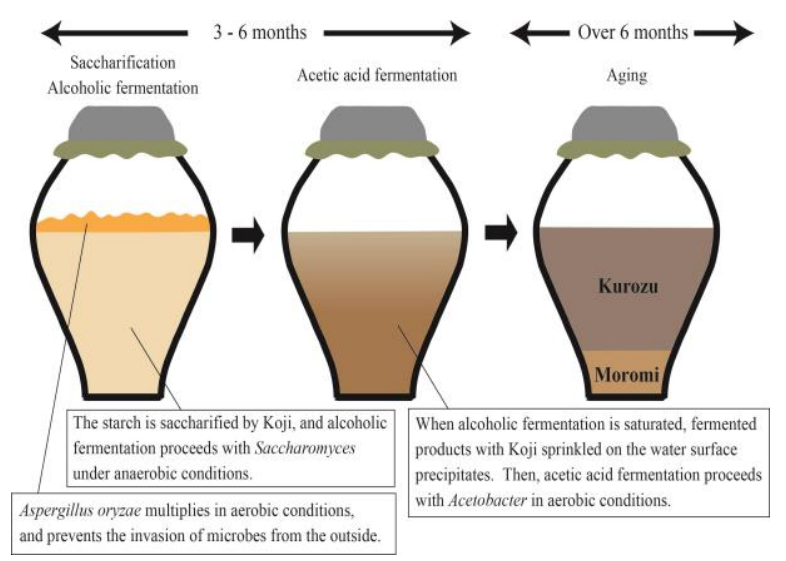

Figure 4. The sequential brewing process of Kurozu
The rice ferments for approximately 3-6 months. Kurozu develops a mellow taste and flavor during the aging process. The typical duration of the aging process ranges from 6 months to 3 years. During the aging process, the color of the vinegar turns from a light color to dark amber. The most common brewed vinegar is made through two phases of saccharification, alcohol fermentation and acetic acid fermentation by $A A B$. A distinctive feature of Kurozu is that acetic acid fermentation does not need the addition of $A A B$. In the initial stages of brewing, the starch of rice is saccharified by Aspergillus oryzae in Koji, and alcohol fermentation proceeds with Koji containing Saccharomyces under anaerobic conditions. Koji sprinkled on the water ferments the initial fermentation products, resulting in the formation of a lid-like layer that prevents the invasion of outside microbes. In the subsequent stage, the surface lid of Koji precipitates and the fermented products enter aerobic conditions. When alcoholic fermentation is saturated, the alcohol produced is converted into acetic acid by $A A B$ in the jar. The insoluble residue (Kurozu-Moromi: KM, Figure 4) precipitates with aging. After fermentation the jars are washed with water and dried outdoors. The jars are never sterilized and are reused directly [2].

COMPONENT: The Japanese Agricultural Standard (JAS) system defines Kurozu as a brewed rice vinegar. Brewed vinegars are made with cereal, fruits, vegetables, or saccharides. Kurozu has to be made with more than 180 grams of rice per $1 \mathrm{~L}$ and has to be amber colored through fermentation and aging. The JAS system approves brewed cereal vinegar containing organic acids, including acetic acid at a concentration of $1.5-8.0 \%$. The Gl Act approves the standard quality of Kurozu in more detail. Kurozu is a vinegar that is colored amber or blackish brown as a result of fermentation and aging. Kurozu includes amino acids (approximately $5 \mathrm{~g} / \mathrm{L}$ ) and organic acids (0.2-0.3\% 
organic acids except acetic acid) derived from unpolished rice. In addition, Kurozu has to conform to the following quality standards:

1. All nitrogen sources comprise more than $0.12 \%$

2. The concentration ratio of amino nitrogen is more than $50 \%$ in all nitrogen sources

3. The concentration of direct reducing sugar is less than $0.30 \%$, as evaluated using the Soy sauce test. The test is used as the analysis method for ingredients in soy sauce, which is a fermentation product of soybean.

Kurozu was previously shown to contain organic acids, amino acids, and inorganic cations. Kurozu is rich in alanine, leucine, lysine, valine, and glycine. Kurozu contains other organic acids such as lactic acid and pyroglutamic acid along with acetic acid. Furthermore, major inorganic cations such as sodium, potassium, and magnesium are found in Kurozu. The compositions are greatly different between products. Koizumi $Y$ et al. reported that 11 kinds of Kurozu contained $0.01-0.48 \%$ saccharide, $724-4,593 \mathrm{mg} / \mathrm{L}$ organic acids without acetic acid, and 569-3,626 mg/L free amino acids. It was estimated that differences in the composition were caused by differences in the raw materials and preparation methods. Ingredients such as amino acids, organic acids, and minerals differ in their density depending on the products and may influence differences in functionality [8]. Kurozu contains peptides, such as Ile-Tyr-Pro, Phe-Phe, GIn-Leu-Pro and Asn-Pro [9].

Over the past decades, the presence of D-amino acids has been shown in bacteria, plants, animals, and fermented foods [10]. Large amounts of D-Ala, D-Asp, and D-Glu have been observed in Kurozu [11]. Shimoji $Y$ et al. reported that Kurozu contained polyphenolic compounds with anti-oxidative activities, such as dihydroferulic and dihydrosinapic acids [12]. Yamagishi $\mathrm{K}$ et al. reported that Kurozu contained histamine, which improves blood fluidity [13]. Recently, Kurozu was shown to contain a lipopolysaccharide compound produced by AAB [14 - 16].

$\mathrm{KM}$ is a product created from fermentation and comprises the insoluble residue, which may be taken in small amounts from the jar. Components of KM have been investigated. Kamata $S$ et al. reported that KM contained saturated fatty acids (palmitate and stearate), unsaturated fatty acids (oleinate and linoleate), and their esters [17]. The odorant compounds in Kurozu were then analyzed. Kurozu contained ketones (e.g. 2-butanone, 2,3-butanedione, 3-hydroxy-2-butanone, 2,3-pentanedione), aldehydes (e.g. benzaldehyde, 2-methyl-butanal, 3-methyl-butanal, acetaldehyde), alcohols (e.g. ethanol, 2-ethyl-1-hexanol), and amines (e.g. 2,3-dimethylpyrazine, trimethylpyrazine) [personal communications, provided by Dr. $\mathrm{H}$ Kanouchi]. These odorant compounds are well known as ingredients in brewed sake made from rice $[18,19]$.

FUNCTIONALITY: Functional studies of Kurozu have dated back to the findings of empiric health benefits. Studies on the functions of Kurozu began in the 1980s, and both in vitro and in vivo investigations of ingredients in Kurozu have been carried out [3]. Recently, clinical studies have also been performed.

Metabolic effects: Health-related properties of Kurozu were initially reported on dyslipidemia. Tanizawa $\mathrm{H}$ et al. reported that Kurozu decreased serum cholesterol levels in both normal and high cholesterol diet-fed mice. Kurozu ingestion also inhibited increases in lipid peroxide levels induced by adriamycin injection in mice myocardium [20]. Oominami and Okuda also reported that supplementation of Kurozu significantly decreased the levels of triglycerides, total cholesterol, and free fatty acids in plasma following corn oil ingestion. Constituents of Kurozu inhibited lipid synthesis stimulation with insulin in rat adipocytes [21]. Concentrated Kurozu administration significantly 
reduced the average size of adipocytes, but the numbers of adipocytes were increased and fatty acid excretion was significantly increased [22].

In a case study, treatment with an extract of Kurozu showed significant decreases in total cholesterol in patients with cardiovascular disease [23]. A randomized control study showed that combined intake of Kurozu and garlic may have the potential to improve serum levels of total cholesterol and low-density lipoprotein cholesterol in a subject population comprised of prehypercholesterolemic and mild-to-moderate hypercholesterolemic subjects [24]. Hamadate $\mathrm{N}$ et al. reported that concentrated Kurozu supplementation significantly decreased body weight, and may decrease body mass index in healthy adults with obesity [25]. Hamadate $\mathrm{N}$ et al. also reported that supplementation of Kurozu decreased hip circumference. Kurozu also increased fat-derived energy consumption while suppressing carbohydrate-derived energy consumption in obese but otherwise healthy subjects [26]. Abe A et al. reported that Kurozu decreased visceral fat accumulation in obese healthy subjects [27]. Oral administration of concentrated Kurozu decreased adipocyte size via inhibition of dietary fat absorption and reduction of PPARY and mRNA levels of fatty acid binding protein 2 in adipocytes in rats [22]. It was reported that acetic acid improved obesity and glucose tolerance. Exogenously administered acetic acid may have effects on lipid metabolism via alteration of glucose transporter 4 and myoglobin gene expression, and it may also function against obesity and obesity-linked type 2 diabetes [28, 29]. Publications about the function of Kurozu evaluated concentrates without acetic acid. It is thought that both the concentration of ingredients in Kurozu and acetic acid contribute to the lipid metabolism improvement.

Recently, Shibayama Y et al. reported that Kurozu inhibited the incidence of hepatic steatosis with a high-fat diet and induced the expression levels of hepatic Sirt1, Pgc-1 $\alpha$, Lpin1, and Igfbp1 in mice [30]. Shibayama $\mathrm{Y}$ et al. also reported that concentrated Kurozu supplementation reduced the onset of hepatic hyperplasia and increased hepatic microRNA-34a, $-149-3 p$, and $-181 a-5 p$ [31]. An effect on glucose metabolism was also reported by Nagano $\mathrm{M}$ et al., where the intake of $\mathrm{KM}$ and Kurozu concentrated liquid prevented increases in blood glucose level in mice [32].

Antioxidants effects: Kurozu contains polyphenolic compounds, and antioxidant effects of Kurozu have been reported. Kurozu scavenged 1,1-diphenyl-2-picrylhydrazyl radicals and decreased antioxidant effect on copper-mediated human low-density lipoprotein oxidation in vitro [33]. In an animal study, an extract of Kurozu inhibited 12-O-tetradecanoylphorbol-13-acetate-induced

edema formation and myeloperoxidase activity in female ICR mouse skin [34]. Kurozu increased the serum biological antioxidant potential level gradually, and after 30 days it was significantly higher compared with the pre-study level. The serum level of diacron-reactive oxygen metabolites and blood filtration time decreased in 10 healthy female subjects [35]. Kurozu improved inflammatory bowel diseases in mice; Fukuyama $\mathrm{N}$ et al. reported that concentrated Kurozu supplementation inhibited inflammation and oxidative stress induced by dextran sulfate sodium treatment in ulcerative colitis [36]. Recently, a notable observation of antioxidant action was reported. Shin $M$ et al. reported that the size of the intracerebral hemorrhage-induced nerve injury lesion and apoptotic neuronal cell death in the striatum was significantly suppressed by Kurozu intake. It was thought that the anti-apoptotic effect occurred with decreasing expression of c-Fos and caspase-3. It was assumed that the decreasing effect of the expression suppressed the oxidative stress and increased the antioxidant level [37]. 
Hematologic and vascular effects: Kurozu influences cardiovascular function and blood fluidity. Fujino $T$ et al. reported that Kurozu ingestion improved red cell filterability in patients with cardiovascular disease [23]. Kurozu also influences function of immune cells. Constituents of Kurozu improved the activity of natural killer (NK) cells, and upregulated interferon- $\gamma$, tumor necrosis factor- $\alpha$, and interleukin-12 in tumor-bearing mice [3]. Kurozu significantly decreased the whole blood filtration time in male long-distance runners [39]. NK cell activity was significantly decreased by training in a Kurozu non-consuming group, but not in a Kurozu-consuming group. It was estimated that Kurozu prevents the degradation of NK cell activity induced by intense training, suggesting its contribution to the physical condition of bicycle racers [40]. Significant differences in blood pressure were observed between a concentrated Kurozu intake group and a non-intake group, both comprised of healthy adult subjects [41]. It was reported that peptides in Kurozu lowered blood pressure [9, 42].

Anti-neoplastic effects: Kurozu inhibited tumor growth in vitro and in vivo. Nanda $\mathrm{K}$ et al. reported that an extract of Kurozu inhibited the proliferation of cancer cell lines in a dose-dependent manner, and apoptosis was caused by G0/G1 arrest through p21 induction [43]. Kurozu inhibited cancer development in vivo. Extract of Kurozu inhibited the incidence and multiplicity of colon adenocarcinoma in rats [44] and tumor growth in tumor-bearing mice $[3,45]$. It was estimated that inhibition effect of tumor growth occurred through upregulation of tumor necrosis factor (TNF)- $\alpha$ [3] and downregulation of matrix metalloproteinase (MMP)-2 [45]. Shizuma T et al. also reported that Kurozu supplementation showed anti-colitis activity, and in 800-4,000 Da fractions, Kurozu had anti-oxidative or anti-nitration effects [46].
KM had similar effects. Fukuyama $\mathrm{N}$ et al. reported that supplementation of KM reduced tumor volume and inhibited MMP activation in tumor-bearing mice [47]. Shizuma T et al. also reported that KM decreased the size of hepatocellular carcinomas and levels of activated matrix MMP-2 and -9 in rats. $\mathrm{KM}$ also prolonged survival in mice with diethylnitrosamine-induced hepatocellular carcinomas [48].

Other effects: Kurozu shows protection effects against hepatic damage. Kurozu inhibits decreases in the cell number of primary cultured cells from rat livers [49]. Concentrated Kurozu decreases IgE levels in the blood in allergy model mice by regulating the tyrosine kinase signaling pathway in the spleen [50]. It was reported that Kurozu contributed to cognitive function. Concentrated Kurozu and KM improved memory impairment in the Morris water maze test, which used senescence-accelerated mouse prone 8 (SAMP8) mice [51]. Ingestion of Kurozu upregulated the expression levels of heat shock protein (HSP) in the brain in SAMP8 mice. It is known that HSP repairs and prevents protein degradation. It was assumed that upregulated HSP prevented the recognition functions of SAMP8 mice [51]. Kurozu and KM suppress inflammatory effects in mice. Ohkura et al. reported that supplementation with Kurozu inhibited lipopolysaccharide (LPS) stimulated TNF- $\alpha$ production in adipocytes and macrophages. KM suppressed pathways of both LPS-stimulated TNF- $\alpha$ production in adipocytes and macrophages and TNF- $\alpha$ induced plasminogen activator inhibitor 1 (PAI-1) production. Kurozu and KM decreased thrombotic tendencies by decreasing PAl-1 production in inflammatory states and have potential as antithrombotic foodstuffs [52]. The representative functions of Kurozu and KM are indicated in Table 1. 
Table 1. Summary of the representative functions of Kurozu and KM

\begin{tabular}{|c|c|c|}
\hline Effect & Species & Ref. No. \\
\hline \multicolumn{3}{|l|}{ Metabolism } \\
\hline Decreased serum cholesterol & Mouse & 20 \\
\hline Decreased levels of triglyceride, total cholesterol and free fatty acid & Rat & 21 \\
\hline Inhibited lipid synthesis & Rat & 22 \\
\hline Increased fatty acid excretion & Mouse & 22 \\
\hline Decreased total cholesterol in serum & Human & 23 \\
\hline Decreased total cholesterol and LDL cholesterol & Human & 24 \\
\hline Decreased body weight and BMI & Human & 25 \\
\hline Decreased hip circumference & Human & 26 \\
\hline Decreased visceral fat accumulation & Human & 26 \\
\hline Inhibited incidence of hepatic steatosis & Mouse & 30 \\
\hline Prevented the increase in blood glucose level & Mouse & 32 \\
\hline \multicolumn{3}{|l|}{ Anti-oxidation } \\
\hline Scavenged radicals & In vitro & 33 \\
\hline Decrease LDL oxidation & In vitro & 33 \\
\hline Inhibited increase of lipid peroxide levels & Mouse & 20 \\
\hline Inhibited myeloperoxidase activity & Mouse & 34 \\
\hline Increased serum biological antioxidant potential level & Human & 33 \\
\hline \multicolumn{3}{|l|}{ Hematologic and vascular } \\
\hline Decreased blood filtration time & Human & 23,40 \\
\hline Decreased NK cell activity & Human & 40 \\
\hline Decreased blood pressure & Human & 41 \\
\hline \multicolumn{3}{|l|}{ Anti-neoplastic } \\
\hline Inhibited the proliferation of cancer cell lines & In vitro & 43 \\
\hline Inhibited growth of colon cancer & Rat & 44 \\
\hline Inhibited growth of colon cancer & Mouse & 45,47 \\
\hline Decreased the size of hepatocellular carcinomas & Rat & 48 \\
\hline \multicolumn{3}{|l|}{ Others } \\
\hline Prevented hepatic cell damage & Rat & 49 \\
\hline Improved allergy & Mouse & 50 \\
\hline Improved memory function & Mouse & 51 \\
\hline Upregulated expression of HSP in the brain & Mouse & 51 \\
\hline
\end{tabular}

Safety concerns: The safety of Kurozu is controversial. A case record reported that a Kurozu supplement induced hepatic dysfunction, but interruption of the Kurozu supplement led to recovery of hepatic function 
[53]. Another case series described that Kurozu might induce intoxication dermatosis, bleeding tendency in eyeball, and gastroenteritis [54]. The properties of food-drug interactions were reported by Iwao $\mathrm{K}$ et al., wherein Kurozu reduced the permeation of glibenclamide in vitro, indicating that Kurozu might modulate the absorption of glibenclamide in vivo [55].

Oguma $\mathrm{T}$ et al. reported that concomitant administration of Kurozu increased the absorption of itraconazole in achlorhydria patients by oral proton pump inhibition [56]. It is well known that drug interactions are induced by the alteration of metabolic enzymes and drug transporters. It was reported that Kurozu did not alter the expression levels of principal drug metabolism enzymes and transporters in rats [57].

\section{CONCLUSION}

The functionalities of Kurozu and KM have been revealed by in vitro and in vivo study. A number of studies have demonstrated that Kurozu and KM improved the symptoms of hypertension, allergies, and hypercholesterolemia, enhanced carbohydrate metabolism, and inhibited tumor growth. However, the functional properties of Kurozu and KM in humans have not yet been explored in detail. Further investigation is needed to determine their functionality in humans.

List of abbreviations: Acetic acid bacteria, $A A B$; Heat shock protein, HSP; Kurozu-Moromi, KM; Lipopolysaccharide, LPS; Low-density lipoprotein, LDL; Matrix metalloproteinase, MMP; Natural killer, NK; Plasminogen activator inhibitor 1, PAI-1; Senescence-accelerated mouse prone 8, SAMP8; Tumor necrosis factor, TNF.
Competing interests: $\mathrm{AF}$ and $\mathrm{MN}$ are employees of Sakamoto Kurozu, Inc.

\section{REFERENCES}

1. Budak NH, Aykin E, Seydim AC, Greene AK, Guzel-Seydim ZB: Functional properties of vinegar. J Food Sci 2014, 79:R757-764.

2. Matunaga K: Kagoshima no Tsubozukuri Kurozu: Registered with the Japan Geographical Identification System. Nippon Shokuhin Kagaku Kogaku Kaishi, 2017, 64:385-388.

3. Ueno $\mathrm{T}$ : The functionality of Kurozu and Kurozumoromimatsu. J Brew Soc Jpn 2011, 106:183-189.

4. Machida $M$, et al.: Genome sequencing and analysis of Aspergillus oryzae. Nature 2005, 438:1157-1161.

5. Machida M, Yamada O, Gomi K: Genomics of Aspergillus oryzae: learning from the history of Koji mold and exploration of its future. DNA Res 2008, 15:173-183.

6. Kitamoto K, Kitagaki $\mathrm{H}$ : Breeding research on sake yeasts in Japan: history, recent technological advances, and future perspectives. DNA Res 2008, 15:173-183. Annu Rev Food Sci Technol 2013, 4:215-235.

7. Bokulich NA, Ohta M, Lee M, Mills DA: Indigenous bacteria and fungi drive traditional kimoto sake fermentations. Appl Environ Microbiol 2014, 80:5522-5529.

8. Koizumi Y, Uehara Y, Yanagida F: The general composition, inorganic cations, free amino acids and organic acids of special vinegars. Nippon Shokuhin Kogyo Gakkaishi 1987, 34:592-597.

9. Funatsu G, Kamuhune M: Patent application for JAPAN Patent Office, 2001-278893.

10. Bastings JJAJ, van Eijk HM, Olde Damink SW, Rensen SS: D-amino Acids in Health and Disease: A Focus on Cancer. Nutrients 2019, 11:E2205.

11. Miyoshi Y, Nagano M, Ishigo S, Ito Y, Hashiguchi K, Hishida N, Mita M, Lindner W, Hamase K: Chiral amino acid analysis of Japanese traditional Kurozu and the developmental changes during earthenware jar fermentation processes. J Chromatogr B Analyt Technol Biomed Life Sci 2014, 
$966: 187-192$.

12. Shimoji Y, Tamura Y, Nakamura Y, Nanda K, Nishidai S, Nishikawa Y, Ishihara N, Uenakai K, Ohigashi H: Isolation and identification of DPPH radical scavenging compounds in Kurosu (Japanese unpolished rice vinegar). J Agric Food Chem 2002, 50:6501-6503.

13. Yamagishi K, Kimura T, Kameyama M, Nagata T, Kikuchi Y: Purification and identification of blood fluidity improvement factor brewed rice vinegar (Kurosu). Nippon Shokuhin Kagaku Kaishi 1998, 45:545-549.

14. Hashimoto M., Obara K., Ozono M., Furuyashiki M., Ikeda T., Suda Y., Fukase K., Fujimoto Y., and Shigehisa H: Separation and characterization of the immunostimulatory components in unpolished rice black vinegar (kurozu). J. Biosci. Bioeng 2013, 116:688-696.

15. Hashimoto M, Ozono M, Furuyashiki M, Baba R, Hashiguchi S, Suda Y, Fukase K, Fujimoto Y: Characterization of a Novel d-Glycero-d-talo-oct-2-ulosonic acid-substituted Lipid A Moiety in the Lipopolysaccharide Produced by the Acetic Acid Bacterium Acetobacter pasteurianus NBRC 3283. J Biol Chem 2016, 291:21184-21194

16. Hashimoto $\mathrm{M}$, Matsumoto $\mathrm{T}$, Tamura-Nakano $\mathrm{M}$, Ozono $\mathrm{M}$, Hashiguchi S, Suda Y: Characterization of outer membrane vesicles of Acetobacter pasteurianus NBRC3283. J Biosci Bioeng 2018, 125:425-431.

17. Kamata S, Nomura T, Hashiguchi K: Analysis of solid components of brewed Vinegar (Kurozu Moromi): Higher Fatty Acids and Metal Ions. Kagoshima University Faculty of Engineering Bulletin 1999, 41:141-144.

18. Isogai A, Utsunomiya $H$, Kanda $R$, Iwata $H$ : Changes in the aroma compounds of sake during aging. J Agric Food Chem 2005, 53:4118-4123.

19. Mimura N, Isogai A, Iwashita K, Bamba T, Fukusaki E: Gas chromatography/mass spectrometry based component profiling and quality prediction for Japanese sake. J Biosci Bioeng 2014, 118:406-414.

20. Tanizawa H, Sazuka Y, Komatsu A, Takino Y: Acute toxicity of Kemezu and its effects on lipid metabolism in male mice. J
Jpn Soc Nutr Food Sci 1983, 36:283-289.

21. Oominami K, Okuda T: Bioactivity of Kurozu (Japanese). Kiso to Rinsho $1983,17: 1597-1602$.

22. Tong LT, Katakura Y, Kawamura S, Baba S, Tanaka Y, Udono M, Kondo Y, Nakamura K, Imaizumi K, Sato M: Effects of Kurozu concentrated liquid on adipocyte size in rats. Lipids Health Dis. 2010, 9:134.

23. Fujino T, Kanaya S, Ariyoshi K, Makizumi K, Kaji Y, Tsuda Y, Ohkura Y: Effect of solid components in brewed vinegar on human serum cholesterol and red cell filterability. J Health Sci Kyushu University 1990, 12:139-141.

24. Nakasone $\mathrm{Y}$, Miura $\mathrm{H}$ : Effect of a traditional Japanese health food made from Kurozu (unrefined black rice vinegar) and garlic combination on serum cholesterol in subjects with prehypercholesterolemia or mild-to-moderate hypercholesterolemia -A randomized, double-blind, placebo-controlled, intervention study-. Jpn Pharmacol Ther $2017,45: 51-60$

25. Hamadate N, Nakamura K, Hirai M, Yamamoto T, Yamaguchi H, lizuka M, Yamamoto E, Iwama Y, Yazawa K: Effect of a dietary supplement containing Kurozu (a Japanese traditional health drink) concentrate on several obesity-related parameters in obese Japanese adults: a randomized, double-blind, placebo-controlled trial. Func Foods Health Dis 2013, 3:310-322.

26. Hamadate $\mathrm{N}$, Seto $\mathrm{K}$, Yazawa K: Effect of a dietary supplement containing Kurozu concentrate on body fat energy metabolism. Jpn J Complem Altern Med 2014, 11:67-74.

27. Abe S, Hasegawa M, Tsuruoka J, Matsumoto Y, Koyanagi S: Effect of dietary supplement containing Kurozu concentrate on visceral fat accumulation. Jpn J Complem Altern Med 2019, 16:13-19.

28. Maruta H, Yoshimura $Y$, Araki A, Kimoto M, Takahashi $Y$, Yamashita H: ctivation of AMP-Activated Protein Kinase and Stimulation of Energy Metabolism by Acetic Acid in $\mathrm{L} 6$ Myotube Cells. PLoS One 2016, 11:e0158055.

29. Yamashita H: Biological Function of Acetic 
Acid-Improvement in Obesity and Glucose Tolerance by Acetic Acid in Type 2 Diabetic Rats. Func Foods Health Dis 2019, 9:276-296. Crit Rev Food Sci Nutr 2016, 56:S171-175.

30. Shibayama Y, Nagano M, Hashiguchi K, Iseki K: Supplementation of concentrated Kurozu, a Japanese black vinegar, reduces the onset of hepatic steatosis in mice fed with a high-fat diet. Func Foods Health Dis 2019, 9:276-296.

31. Shibayama Y, Nagano M, Fujii A, Hashiguchi K, Morita S, Kubo Y, Nakagawa T: Effect of concentrated Kurozu, a traditional Japanese vinegar, on expression of hepatic miR-34a, -149-3p, and $-181 a-5 p$ in high-fat diet-fed mice. Func Foods Health Dis 202-, 10:1-17.

32. NaganoM, Fujii A, Aoyama Y, Kurita M, Fujii M: Effects of Kurozu Moromi powder and Kurozu concentrated liquid on carbohydrate metabolism. Jpn Pharmacol Ther 2006, 34:199-206.

33. Yamaji K, Nagano M, Maruyama I: Radical scavenging activity of Kurozu (Brewed rice vinegar) on 1,1-diphenyl-2-picrylhydrazyl and its antioxidant effect on human low-density lipoprotein. J Jpn Soc Nutr Food Sci 2001, 54:89-93.

34. Nishidai S, Nakamura Y, Torikai K, Yamamoto M, Ishihara N, Mori $\mathrm{H}$, Ohigashi $\mathrm{H}$ : Kurosu, a traditional vinegar produced from unpolished rice, suppresses lipid peroxidation in vitro and in mouse skin. Biosci Biotechnol Biochem 2000, 9:1909-1914.

35. Nagashima M, Saito K: Antioxidant activity of the new black vinegar "IZUMI". J Nutr Health Aging 2010, 10:845-849.

36. Fukuyama N, Shizuma T, Ishiwatari K, Nagano M: Effect of Kurozu ingestion on inflammatory bowel diseases in mice (Japanese). J Jpn Soc Parenteral Enteral Nutrition 2008, 23:S138.

37. Shin M, Nishiyama T, Harano T, Tanaka T, Fukunaga T, Yukihira T, Doi A: Effect of Kurozu on intrastriatal hemorrhage-induced brain damage in rats. J Kumamoto Health Sci University 2019, 16:49-57.

38. Saito K, Maruyama I: The effects of Kurozu (a brewed rice vinegar) on the deformability of erythrocytes in male long distance runners. Hemorheol Related Res 2004, 7:25-31.

39. Nagashima M, Saito K, Hagi Y: Effect of Kurozu on Peripheral Blood Cells and NK Cell Activity in Student Bicycle Racers. Jpn J Nutr Diet 2009, 67:107-111.

40. Hamadate N, Kyo H, Matsumoto Y, Shikura M, Mizukami C, Seto K, Uebara K, Suzuki N: Effect of a dietary supplement containing Kurozu concentrate on blood pressure, QOL and TCM constitution. Jpn J Complem Altern Med 2014, 11:95-102.

41. Kajimoto S, Ooshima Y, Tayama K: Effect of vinegar-added beverages on hypotensive action in healthy or mild hypertensive subjects (Japanese). J Nutritional Food 2003, 6: 51-68.

42. Nanda K, Miyoshi N, Nakamura Y, Shimoji Y, Tamura Y, Nishikawa Y, Uenakai K, Kohno H, Tanaka T: Extract of vinegar "Kurosu" from unpolished rice inhibits the proliferation of human cancer cells. J Exp Clin Cancer Res 2004, 23:69-75.

43. Shimoji $Y$, Kohno $H$, Nanda K, Nishikawa $Y$, Ohigashi $H$, Uenakai K, Tanaka T: Extract of Kurosu, a vinegar from unpolished rice, inhibits azoxymethane-induced colon carcinogenesis in male F344 rats. Nutr cancer 2004, 49:170-173.

44. Shizuma T, Ishiwata K, Kanazawa $H$, Nagano $M$, Mori $H$, Fukuyama N: Inhibitory effect of Kurozu on proliferation of human colon cancer cells in a mouse model in vivo. J Jpn Soc Parenteral Enteral Nutr 2007, 22:65-71.

45. Shizuma T, Nagano M, Fujii A, Mori H, Fukuyama N: Therapeutic effects of four molecular-weight fractions of Kurozu against dextran sulfate sodium-induced experimentalcolitis. Turk J Gastroenterol 2011, 22:376-381.

46. Fukuyama N, Jujo S, Ito I, Shizuma T, Myojin K, Ishiwata K, Nagano M, Nakazawa H, Mori H: Kurozu moromimatsu inhibits tumor growth of Lovo cells in a mouse model in vivo. Nutrition 2007, 23:81-86

47. Shizuma T, Ishiwata K, Nagano M, Mori H, Fukuyama N: Protective effects of fermented rice vinegar sediment (Kurozu moromimatsu) in a diethylnitrosamine-induced 
hepatocellular carcinoma animal model. J Clin Biochem Nutr 2011, 49:31-35.

48. Fujii M, Hou D, Arimura M, Chiwata T, Suzuki M, Nagan M: Effect of Kurozu (Brewed Rice Vinegar) on Maintenance of Primary Culture of Rat Hepatocytes. Food Sci Technol Res 1999, 5:97-98.

49. Awane S, Nishi K, Ishida M, Nagano M, Hashiguchi K, Fujii A, Sugahara T: Inhibitory effect of Japanese black vinegar on IgE-mediated degranulation of RBL-2H3 cells and a murine model of Japanese cedar pollinosis. Cytotechnology 2018, 70:961-974.

50. Kanouchi H, Kakimoto T, Nakano H, Suzuki M, Nakai Y, Shiozaki K, Akikoka K, Otomatu K, Nagano M, Matsumoto M: The Brewed Rice Vinegar Kurozu Increases HSPA1A Expression and Ameliorates Cognitive Dysfunction in Aged P8 Mice, PLOS ONE 2016, 11:e0150796.

51. Ohkura N, Negishi F, Fujii A, Kanouchi H, Oishi K, Atsumi G, Nagano M: Effects of fermented rice vinegar Kurozu and its sediment on inflammation-induced plasminogen activator inhibitor 1 (PAI-1) increase. Food Nutrition Sci 2018, $9: 235-246$.

52. Oono K, Yokoyama T, Matsusaki R, Misago T, Hashiyatani R, Fujimaki K, Nakanishi T: A case report of food-induced liver injury might cause by Kurozu ingestion with positive for drug-induced lymphocyte stimulation test (proceeding report, Japanese). J Jpn Soc Parenteral Enteral Nutr 2010, 25:418.

53. National Institute of Health and Nutrition Japan. Information system on safety and effectiveness for health foods. https://hfnet.nibiohn.go.jp/

54. Iwao K., Kawai RT., Oda M., Kobayashi M, Saitoh H: Physicochemical interactions of metformin hydrochloride and glibenclamide with several health foods. Yakugaku Zasshi 2008, 128:1341-1345.

55. Oguma T, Tabata $H$, Aihara K, Matsumoto $M$, Kagioka $H$, Nagano $M$, Fukui $M$ : Influence of Black Vinegar on Itraconazole Absorption. J Jpn Assoc Infect Dis 2009, $83: 369-374$
56. Shibayama Y, Nagano M, Fujii A, Taguchi M, Takeda Y, Yamada K: Safety Evaluation of Black Rice Vinegar (Kurosu) from a Jar on Food-drug Interaction: 30-day Ingestion Study on Expressions of Drug Metabolism Enzymes and Transporters in Rats. J Health Sci 2010, 56:712-716. 